Pollcy Research

WORKING PAPERS

International Trade

International Econo .ics Department

The World Bank

July 1993

WPS 1163

\title{
Domestic Distortions and International Trade
}

\author{
James E. Anderson \\ and \\ J. Peter Neary
}

The Trade Restrictiveness Index provides a theoretically consistent and empirically feasible framework for investigating the trade implications of such domestic distortions as production taxes and subsidies. 


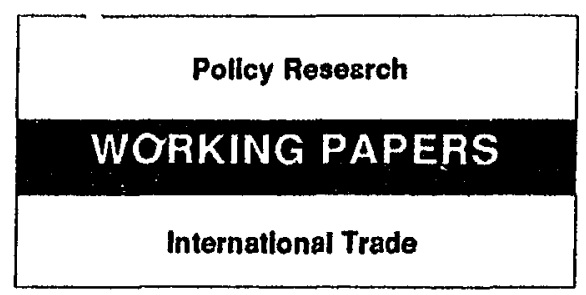

WPS 1163

This paper - a product of the International Trade Division, International Economics Department - is part of a larger effort in the department to measure the effects of protection policy. The study was funded by iile Bank's Research Support Budget under research project "The Cost of Protection index"(RPO 676-49). Copies of this paper are available free from the World Bank, 1818 H Street NW, Washington, DC 20433. Please contact Dawn Gustafson, room S7-044, extension 33714 (July 1993, 30 pages).

Trade is affected not only by taxes and subsidies that affect producers and consumers of goods, but also, indirectly, by taxes and subsidies that affect nontraded goods or factors of production.

Anderson and Neary show how the Trade Restrictiveness Index (TRI) may be extended to incorporate these types of distortions. Again, the value of the TRI gives the equiproportionate change in the prices of traded goods, which would compensate for a given change in all distortions, both in traded and nontraded goods and in factor markets.

Anderson and Neary, who developed the theory of the TRI, show how to apply it in practice, drawing on a larger study by Anderson and Bannister of changes in Mexican agricultural policy between 1985 and 1989. Adapting the TRI to a partial equilibrium context allows existing estimates of key demand and supply elasticities to be incorporated into he Index; and the basic formula is adapted to take account of sume special features of Mexican agricultural markets.

The TRI shows a great increase in restrictiveness in 1986 and especially 1987 , followed by major reductions in restrictiveness in 1988 and 1989. The cumulative effect: a 49.9 percent fall in trade restrictiveness over the four years.

The major, although not the only, source of changes in trade restrictiveness were changes in producer subsidies, especially for maize. These trends are not captured by changes in indices for consumer and producer subsidy equivalents, which the authors also present. Indeed, in a number of years at least one of the ad hoc indices changed in the opposite direction to the change in the corresponding welfare-based index. 
DOMESTIC DISTORTIONS AND INTERNATIONAL TRADE

James E. Anderson

Boston College

and.

J. Peter Neary

University College Dublin.

University of Ulster and CEPR 


\section{Summary}

Anderson and Neary address the problem of measuring the trade restrictiveness of purely domestic policies such as production taxes and subsidies. It is widely accepted that such policies distort trade patterns and attempts have been made to quantify their impact. However, these have typically calculated producer and consumer subsidy equivalent indices, which are averages of subsidies weighted by the production or constmption shares of the subsidised commodities. Such indices lack any theoretical foundation and have obvious practical limitations: for example, highly taxed commodities are given a low weight whereas intuitively they should be heavily weighted in assessing the overall trade restrictiveness of the tax and subsidy structure. Anderson and Neary propose alternative indices which avoid these difficulties and are firmly based in welfare economics, yet at the same time can be estimated feasibly with relatively low data requirements.

The approach proposed by Anderson and Neary builds on recent work of theirs on the Trade Restrictiveness Index (TRI), which aggregates the effects on trade of a complicated pattern of trade distortions such as tariffs and quotas. Extending the TRI to encompass domestic distortions has a straightforward intuitive interpretation: the value of the Index answers the question "What uniform tariff woild have the same effect on welfare and the trade balance as a given structure of domestic consumer and producer taxes and subsidies?" The Index can also be applied to a comparison between two distorted situations rather than to a comparison between an initial distorted situation and free trade; in that case, it gives the uniform "tariff factor surcharge," or change in domestic prices to both consumers and producers, which would compensate for the move from the initial to the new distorted situation.

The authors show that changes in this Index equal a weighted average of changes in the distorted prices facing consumers and producers, where the weights are marginal welfare weights reflecting the welfare costs of distortion changes. They note that their Index is preferable to the standard ad hoc producer and subsidy equivalent indices on two counts. Firstly, it uses these marginal weights rather than average weights which bear no relation to the degree of restrictiveness of the distortions. Secondly, the TRI aggregates correctly over consumer and producer distortions, something which cannot be done using the ad hoc indices. 
Taxes ard-subsidies affecting the producers and consumers of traded goods are only one form of domestic distortion which impacts on trade. Taxes and subsidies in the markets for nontraded goods or for factors of production also distort trade indirectly. Anderson and Neary show how the TRI may be extended to incorporate these types of distortions. Once again, the value of the TRI gives the equiproportionate change in the prices of traded goods which would compensate for a given change in all distortions, both in traded and in non-traded goods and in factor markets.

Having developed the theory of the TRI, Andersor and Neary. proceed to illustrate how it may be applied in practice, drawing on a larger study ' $y$ Anderson and Bannister of the changes in Mexican agricultural policy between 1985 and 1989. Specialising the TRI to a partial equilibribn context allows existing estimates of key demand and supply elasticities to be incorporated into the Index; and the basic formula is adapted to take account of some special features of Mexican agricultural markets.

The results of the empirical study are of considerable interest. The TRI shows a large increase in -restrictiveness in 1986 and especially in 1987 followed by major reductions in restrictiveness in 1988 and 1989 . The cumulative effect of these changes is a $40.9 \%$ fall in trade restrictiveness over the four-year period. Examination of the disaggregated components of the Index reveal that the major, though not the sole, source of changes in trade restristiveness over the period was changes in producer subsidies, especially to the major crop, maize. These trends are not captured by the changes in the consumer and producer subsidy equivaleni indices, which the authors also present. Indeed, in a number of years the change in at least one of the ad hoc indices is in the opposite direction to the change in the corresponding welfare-based index.

The authors conclude that the TRI provides a theoretically consistent ano empirically feasible framework for investigating the trade implications of domestic distortions. 


\section{Introduction:}

It is widely appreciated that govemment policies of a purely domestic nature can have major implications for a country's international trade. To give just one example, such implications have been widely discussed in the context of the current GATT round, in which US negotiators have insisted that intra-EC agricultural policy should be viewed as trade-distorting. However, analysts and negotiators have not hitherto had access to a conceptual framework which would allow the trade effects of domestic policies to be measured in a consistent way. In this paper, we propose such a framework and show how it may be implemented empirically.

Of course, other attempts have been made to quanify the overall distortionary effects of domestic policirs. These have involved constructing empirically based indexes such as producer or consumer subsidy equivalents. ${ }^{1}$ However, such measures have no theoretical foundation. Moroeover, since they use the shares of different sectors in production or consumption as weignts, they are likely to be systematically biased: for example, sectors whose output levels are reduced by high taxation are assigned low weights whereas their "true" weights should be higher. By contrast, we show below that our approach is based firmly on welfare economics and correctly uses marginal rather than average production and consumption shares as weights.

The approach we propose draws on our recent work (Anderson and Neary, 1990, 1991) which dealt with trade distortions only. There we developed a scalar index equal to the equiproportionate rate of trade restriction which is equivalent (in welfare terms) to a given system of trade policies. For example, if trade is restricted by tariffs only, then our index equals the uniform tariff which is welfare-equivalent to the initial tariff structure. ${ }^{2}$ We have shown that our index has a sound basis in standard welfare economics: it serves to synthesise

"This paper was written as part of a World Bank project on "The Cost of Protection Index" (RPO 676-49). For helpful comments, we are grateful to Geoff Bannister and to participants in seminars at the World Bank, the University of Konstanz, and the EEA 92 Conference in Dublin.

'See, for example, OECD (1991).

${ }^{2}$ For an early dzvelopment of this approach, see Corden (1966). 
the literature on "distance function" measures of welfare change $e^{3}$ with that on the measurement of the cost of protection. ${ }^{4}$ We have also argued that the index may be used in at least two alternative ways: either as an organising principle for reporting the results of computable general equilibrium mudels; or, with appropriate additional assumptions, us a technique for constructing approximate local measures of changes in policy restrictiveness in either partial or general equilibrium models. ${ }^{5}$ In either case, the use of our index permits consistent comparisons of the restrictiveness of trade policy to be made across countries and across time.

All this previous work has considered only trade distortions, and assumes that the domestic economy is undistcrted. In the present paper, we show how this appreach may be extended to incorporate purely domestic distortions. In effecr, we ask what uniform tariff would be equivalent to a given set of domestic policy instruments. Measuring the trade impact of domestic policies in this way has obvious potential as an input into trade negotiations and as a summary of how a country's trade orientation has evolved. Of course, if the method is to be useful it is essential that it can be implemented empirically. We t'erefore devote considerable attention to showing that this can indeed be done and to illustrating some of the shortcuts that are necessary in empirical work.

${ }^{3}$ See Debreu (1951), Deaton (1979) and Diewert (1985).

4 Standard references include Foster and Sonnenschein (1970), Bertrand and Vanek (1971), Bruno (1972), Lloyd (1974) and Hatta (1977); the literature has been surveyed by Corden (1984) and Dixit (1987); and our index also takes account of recent extensions of the literature to incorporate the costs of quota as well as tariff protection by Corden and Falvey (1985), Falvey (1988), Neary $(1988,1989)$ and Anderson and Neary (1992a).

s For partial equilibrium applications see Anderson (1991) and Anderson and Neary (1992b); work on a general equilibrium $\mathrm{JF} \mathrm{F}^{\mathrm{i}}$ cation is in progress. 
The plan of the paper is as follows. Section II draws on Anderson and Neary (1992b) to extend the theory of our measure, the Trade Restrictiveness Index (TRI), ${ }^{6}$ to the case where domestic taxes or subsidies drive a wedge brtween the prices faced by producers and consumers. The relationship between cur index and the ad hoc producer and consumer subsidy equivaleat indices in considered in Section III. Sections $\mathrm{V}$ and $\mathrm{V}$ then examine how the Index can be adapted to allow for the effects of other types of domestic distortions, in markets for non-traded goods or factors of production. The results of a pilot application of the Index, which draws on a larger study of Mexican agriculture by Anderson and Bannister (1992), are presented in Section VI. Finally, Section VIII makes some concluding remarks.

6 In our first presentation of the measure, Anderson and Neary (1990), we called it the "coefficient of trade utilisation" reflecting its parallel with the "coefficient of resource utilisation" of Debreu (1951). That paper considered quota restrictions only whereas Anderson and Neary (1992b) extended the measure to incorporate both tariffs and quotas. In the present paper we consider only price distortions but it is straightforward, if tedious, to incorporate quantitative restrictions by adapting the methods of our earlier papers. 


\section{The Tariff Equivalents of Distortions in Traded Goods Markets}

In this section, we introduce notation and assumptions alis develop the theory of the Trade Restrictiveness Index (TRI) for the case where the oniy forms of policy intervention are taxes or subsidies to domestic producers or consumers in traded goods markets.

Throughout the paper we assume that the economy under consideration is small, trading with the rest of the world an untaxed numeraire good and $n$ other $\xi$ rods whose given price vector is denoted $\mathrm{p}^{*}{ }^{7}$ Because of domestic policies, this may differ from the price vector facing domestic producers, $p$, and from the price vector facing domestic consumers, $q$. Thus a particular traded good indexed by i may have a subsidy to production, so that $\mathrm{p}_{i}-\mathrm{p}_{i}^{*}$ is positive, or $a$ tax, so that $p_{i}-p_{i}^{*}$ is negative. In addition, it may have a subsidy to consumption, so that $q_{i}-q_{i}^{*}$ is negative, or a tax, sc that $q_{i}-q_{i}^{*}$ is positive. If the only form of intervention is trade poliey, domestic producer and consumer prices are equal; thus, an import tariff (or export subsidy) is equivalent to an equiproportionate producer subsidy and consumer tax: $p_{i}=q_{i}>$ $p_{i}^{*} ;$ and an import subsidy (or export tax) is equivalent to an equiproportionate producer tax and consumer subsidy: $p_{i}=q_{i}<p_{i}^{*}$. In the analysis which follows, it tums out to be most convenient to treat the producer and consumer prices themselves rather than the disturtion wedges as the policy instruments. Since world prices are assumed fixed, these alternative procedures are of course equivalent.

The specification of the economy's behavioral equations uses standard dual techniques. ${ }^{8}$ On the supply side, we assume until Section IV that production is carried out efficiently under competitive conditions. It may therefore be characterised by a GNP function, $g(p, v)$, which gives the maximum value of output that can be produced facing prices $p$, given the economy's factor endowments (denoted by the vector $v$ ) and technology. By Hotelling's Lemma, the price derivatives of this function, $g_{p}(p, v)$, give the economy's general equilibrium net supply functions, $y(p, v)$. On the demand side, we abstract from distribution to concentrate on

\footnotetext{
${ }^{7}$ In Anderson and Neary (1992b), we discuss how endogenous world prices can be incorporated. ${ }^{8}$ See Dixit and Norman (1980) for an overview.
} 
efficiency issues and assume that the economy can be represerted by a single aggregate household. The behavior of this household is characterised by an expenditure function, $e(q, u)$, which gives the minimum expenditure needed to attain utility level $u$ facing prices $q$. By Shephard's Lemma, the price derivatives of this function, $e_{q}(q, u)$, give the (compensated) consumer demand functions, $x(q, u)$.

The existence of domestic policy distortions generates net government revenue, which may be positive or negative, equal to $\left(q-p^{*}\right)^{\prime} x-\left(p-p^{*}\right)^{\prime} y^{9} \quad$ Following standaril convention, we assume that this is redistributed to (or, if negative, collected from) the private sector in a $1:$ mp. sum fashion. The specification of equilibrium can now be completed by introducing a new function, the Balance of Trade Function, defined as the excess of consumer expenditure over incosine (the latter in turn equal to the sum of GNP and net government revenue):

$$
B(p, q, u) \equiv e(q, u)-g(p, v)-\left(q-p^{*}\right)^{\prime} x(q, u)+\left(p-p^{*}\right)^{\prime} y(p, v) .
$$

Note that the Balance of Trade Function is defined over the policy variables $p$ and $q$; and that it is conditional on world prices $\mathrm{p}^{*}$ as well as on all the other exogenous variables underlying the general equilibrium of the economy. Ignoring any exogenous international transfers, a full equilibrium of the economy can be characterised by the requirement that $B(p, q, u)$ is zero.

While our main interest is in deveioping a measure of the tariff equivalent of an arbitrary set of distortions. it is helpful to digress and derive first the relationship between changes in distortions and changes in welfare. This is easily done by setting (2.1) equal to zero and totally differentiating, to obtain:

$$
B_{u} d u=-B_{p}^{\prime} d p-B_{q}{ }^{\prime} d q \text {, }
$$

where:

$$
\begin{aligned}
& B_{u} \equiv\left[1-\left(q-p^{*}\right)^{\prime} x_{]}\right] e_{u}, \\
& -B_{p}^{\prime} \equiv-\left(p-p^{*}\right)^{\prime} y_{p} \\
& -B_{q}^{\prime} \equiv\left(q-p^{*}\right)^{\prime} x_{q} .
\end{aligned}
$$

${ }^{9}$ All vectors are column vectors and a prime (') denotes a transpose. 
The interpretation of (2.2) is relatively straightforward and familiar. The left-hand side gives the change in utility multiplied by a parameter $\mathrm{B}_{4}$ which may reasonably be assumed to be positive. ${ }^{10}$ Utility therefore rises whenever the rigii-hand sidc is positive. To interpret this, recall that the matrix of price derivatives of supply, $y_{p}$, is positive semi-definite (since $g$ is convex in $p$ ) and that the matrix of compensated price derivatives of demexd, $x_{q}$, is negative semi-definite (since $e$ is concave in $q$ ). It follows that if there is only a single distortion in either production or consumption, welfare will rise if its mag.aitude is progressively reduced; an ${ }^{\circ}$ if there are many distortions, welfare will rise if they are reduced in an equipro, ortionate manner (i.e., if $d p=\left(p-p^{*}\right) d \alpha$ or $d q=\left(q-p^{*}\right) d \beta$, where $d \alpha$ and $d \beta$ are negative scalars). More generally, any reduction of distortions is likely to raise welfare but, especially if it diverges significantly from pioportionality, it need not do so."

lie are now ready to define the Trade Restrictiveness Index (TRI). Consider the discrete comparison between two equilibria, indexed by " 0 " and " 1 ". Since international payments balance in both periods:

$$
B\left(p^{0}, q^{0}, u^{0}\right)=B\left(p^{1}, q^{1}, u^{i}\right)=0 .
$$

The TRI is now defined as the scalar factor of proportionality, or tariff factor surcharge, ${ }^{12}$ by

${ }^{10}$ This term equals the marginal cost of utility multiplied by a "distortion multiplier" type of expression. If the term were not positive, the oconomy would be so distorted that a negative transfer would raise welfare, in which case the policy reform problem is trivial. Alternative sufficient conditions for the term to be positive are that equilibrium be stable under a utilityadjustment mechanism or that all goods be normal (the latter follows from the cordition that $q^{\prime} x_{I}$ equals $1-p_{0} x_{01}$, where $p_{0}$ is the price of and $x_{01}$ is the income derivative of demand for the numeraire).

"Versions of the "concertina rule," first put forward by Bertrand and Vanek (1971), niay also be developed for this model, to show that a reduction in the highest production or consumption distortion must raise welfare, provided the good in question is a net substitute for all other goods.

${ }^{12}$ We use the term "tariff factor" to refer to one plus the tariff rate; and we use the term "tariff factor surcharge" to refer to a tax on imports which multiplies the domestic prices of tariffconstrained goods by the tariff surcharge rate. This is not the same as raising tariffs by a uniform proportionate rate, except when the starting point is free trade. 
which period-1 prices would have to be adjusted to ensure balanced trade wher utility is at its period- 0 level. Formally, denoting the TRJ by $\Delta$ :

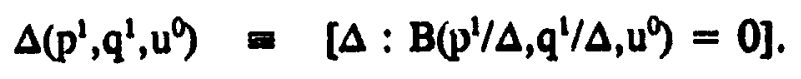

To interpret this Index, we begin by considering two special cises. The first of these is where $p^{1}=q^{1}$ and $p^{0}=q^{0}$; in this case, tariffs are the only form of cistortion and the Index measures the uniform tariff factor surcharge which is welfare-equivalent to the initial tariff structure: i.e., to compensate for a change in tariff policy from $\left(p^{0}-p^{*}\right)$ to $\left(p^{1}-p^{*}\right)$, it would be necessary to alter domestic prices by imposing a uniform tariff factor surcharge equal to the inverse of $\Delta .{ }^{13}$ The second special case is where $\mathrm{p}^{1}=\mathrm{q}^{1}=\mathrm{p}^{*}$; in this case, the new equilibrium is undistorted (both producers and corsumers face world prices) and to compensate for the move to free trade it would be necessary to impose a uniform tariff which raised prices by the inverse of $\Delta$. Figure 1 illustrates this second case for a single good where $p^{0}>p^{*}>q^{0}$, implying that both producers and consumers are subsidised in the initial equilibrium. The resulting welfare loss equals the sum of the producer surplus triangle $A B C$ and the consumer surplus triangle DEF. By construction, the tariff factor $1 / \Delta$ is welfare-equivalent to the policy vector $\left(p^{0}, q\right)$ since it gives rise to an identical welfare loss, equal to the sum of the producer and consumer surplus triangles AGH and DIJ."

Turning to the general case, in which the new equilibrium need not be undistorted $\left(p^{1} \neq q^{1} \neq p^{*}\right)$, the Index measures (one plus) the uniform tariff surcharge which is welfareequivalent to the initial equilibrium. For a given initial equilibrium $\left(p^{0}, q^{q}\right), \Delta$ is greater the further the new equilibrium is from the undistorted equilibrium (in which $\mathbf{p}^{1}=\mathbf{q}^{1}=\mathbf{p}^{*}$ ). Thus,

${ }^{23}$ In this special case, the index is identical to the version sonsidered in our earlier paper, Anderson and Neary (1992b).

${ }^{14}$ Note that the tariff factor $1 / \Delta$ gives rise to an import volume GJ which is lower than that in the free trade equilibrium, AD. By contrast, the same ranking need not hold for the import volume in the initial equilibrium, which equals BD plus EF. Of course, in general equilibrium, changes in the import volume in one market are balanced by opposing changes in import volumes in all other markets, so overall trade balance is maintained. 
for given $\left(p^{0}, q^{9}\right)$, a rise in $\Delta$ corresponds to an increase in the trade restrictiveness of domestic taxes and subsidies. ${ }^{13}$

The level of the TRI is conceptually important. However, in many applications it is orly practicable to estimate changes in the Index, so we must turn to interpret them. Totally differentiating (2.7) for a given reference level of utility, $u^{0}$, gives the effect on the Index of changes in the period-1 distortions:

$$
\Delta\left(B_{p}^{\prime} d p+B_{\rho}^{\prime} d q\right)-\left(B_{p}^{\prime} p+B_{q}^{\prime}\right) d \Delta=0 .
$$

Cor-arting to proportional changes (writing $\hat{\Delta}$ for $d \Delta / \Delta$, etc.), this becomes:

$$
\hat{\Delta}=\frac{\sum_{i}\left(B_{i} p_{i}\right) p_{i}+\sum_{j}\left(B_{j} q_{j}\right) \dot{q}_{j}}{B_{p}^{\prime} p+B_{q}^{\prime} q},
$$

where $B_{i}$ and $B_{j}$ denote $\partial B / \partial p_{i}$ and $\partial B / \partial q_{j}$, respectively. From (2.2), the numerator of (2.9) equals (minus) the welfare effect of the distortion changes. This is normalised by the expression in the denominator: $B_{p}^{\prime} p+B_{q}^{\prime} q$. To interpret this, note that the derivatives of $B$ with respect to the distorted prices may be interpreted as the "shadow quantities" associated with the distortions, and the denominator is the sum of these shadow quantities times the appropriate prices. Hence, the denominator may be interpreted as the "shadow value of distorted activity." Note, however, that it need not be positive: this depends on how close to proportionality are the distortions and on whether they drive home prices above or below world prices. Thus, the change in $\Delta$ need not have the same sign as the change in welfare: a movement towards a tax/subsidy regime which is equivalent to a greater degree of trade restrictiveness may be associated with either a rise or a fall in welfare. Finaliy, note that all the terms needed to

${ }^{15}$ This is why, in defining the TRI in (2.7), we adopt the convention of deflating $p$ and $q$ by $\Delta$ rather than sialing them up by $\Delta$, which superficially might seem more attractive. 
calculate $\hat{\Delta}$ are estimable. Our approach therefore provides the basis of an operational method of measuring the restrictiveness of producer and consumer distortions which (because of the appropriate normalisation) permits consistent comparisons across countries and across time. 


\section{Ad Hoc versus True Producer and Consumer Subsidy Equivalents}

Inspecting equations (2.7) and (2.9) in the previous section, it is clear that the TRI (in both level and rate of change form) has two distinct components, corresponding to changes in producer and consumer taxes and subsidies respectively. In this section we spell out this decomposition, which is of interest in itself and also allows a comparison of our approach with the commonly used ad hoc measures of producer and consumer subsidy equivalents.

Returning to (2.7), consider the outcome of defining a distortion index separately for production and consumption distortions, rather than for both together. For production distortions, this leads to a true producer subsidy equivalent index, $\Delta^{p}$, defined as:

$$
\Delta^{p}\left(p^{1}, q^{1}, u^{q}\right)=\left[\Delta^{p}: B\left(p^{1} / \Delta^{p}, q^{1}, u^{q}\right)=0\right] .
$$

Here, $\Delta^{p}$ gives the equiproportionate change in production distortions alone which is welfareequivalent to the policy change from period 0 to period 1 . The rate of change of this index is analogous to that of the full index $\Delta$ and is calculated in the same manner:

$$
\hat{\Delta}^{p}=\frac{\sum_{i}\left(B_{i} p_{1}\right) p_{i}}{B_{p}^{\prime} p} .
$$

This may be compared with the change in the ad hoc producer subsidy equivalent index:

$$
P S E=\frac{\sum_{i}\left(y_{1} p_{i}\right) p_{1}}{y^{\prime} p} .
$$

Comparing (3.2) and (3.3), and recalling the definition of the $B_{i}$ parameters in (2.4), it is clear that the difference between the two indices hinges on the use of average production shares as weights in (3.3) as opposed to marginal production shares in (3.2). ${ }^{16}$

\footnotetext{
${ }^{16}$ The numerator of the average weights is just quantity times price, whercas that of the marginal weights equals, from (2.5), the sum of each distortion times the rate of change of each distorted activity, times the price. This switch from a linear to a quadratic structure is exploited by Anderson (1992) to show that the TRI can be decomposed into two terms, one a function of the average tariff and the other a function of the generalised variance of tariffs.
} 
An identical series of derivations can be carried out for consumption distortions. Firstly, we can define a true consumer subsidy equivalent index:

$$
\Delta^{q}\left(p^{1}, q^{1}, u^{q}\right) \equiv\left[\Delta^{q}: B\left(p^{1}, q^{1} / \Delta^{q}, u^{q}\right)=0\right] .
$$

Once again, the proportionate change in this index is a weighted average of the distortion changes, where the weights are marginal consumption shares:

$$
\hat{\Delta}^{q}=\frac{\sum_{j}\left(B q_{j}\right) \dot{q}_{j}}{B_{q}^{\prime} q} .
$$

This should be compared to the change in the ad hoc consumer subsidy equivalent:

$$
C S E=\frac{\sum_{j}\left(x_{j} q_{j}\right) q_{j}}{x^{\prime} q},
$$

where average consumption shares are inappropriately used as weights.

Bringing together these results, the change in the full Trade Restrictiveness Index can be expressed as a weighted average of the changes in the true producer and consumer subsidy equivalent indices: ${ }^{17}$

$$
\hat{\Delta}=\lambda \hat{\Delta}^{p}+(1-\lambda) \hat{\Delta}^{q},
$$

where the weights reflect the contributions of production and consumption distortions to the total shadow value of distorted activity:

$$
\lambda=\frac{B_{p}^{\prime} p}{B_{p}^{\prime} p+B_{q}^{\prime} q} .
$$

This serves to place in perspective the advantages of our approach over the commonly used

${ }^{17}$ This result is an approximation only, since the changes in the three indices, $\Delta, \Delta^{p}$ and $\Delta^{q}$, are evaluated at different points, as a comparison of the arguments in equations (2.7), (3.1) and (3.4) shows. 
alternative: it uses appropriate weights and it also correctly aggregates the effects of changes in the two types of distortions.

Finally, our approach permits an alternative decomposition of the change in trade restrictiveness: by commodity rather than by type of instrument. For some purposes it may be of interest to establish which commodities have contributed most to the overall change in trade restrictiveness. By analogy with (3.7), an appropriate method of doing this is to decompose the change in $\Delta$ as follows:

$$
\hat{\Delta}=\sum_{j} \mu \hat{\Delta}_{j},
$$

where $\hat{\Delta}_{j}$ is the change in the distortion index for commodity $j$, defined as:

$$
\hat{\Delta}_{j}=\lambda_{j} p_{j}+\left(1-\lambda_{j}\right) \hat{q}_{j} .
$$

Here the $\mu_{j}$ and $\lambda_{j}$ parameters are weights, giving respectively the contribution of distortions in the market for good $j$ to the total shadow value of distorted activity and the contribution of production distortions to the shadow value of distorted activity in good $\mathrm{j}$ :

$$
\mu_{j}=\frac{\left(\partial B / \partial p_{j}\right) p_{j}+\left(\partial B / \partial q_{j}\right) q_{j}}{B_{p}^{\prime} p+B_{f}^{\prime} A}
$$

$$
\lambda_{j}=\frac{\left(\partial B / \partial p_{j}\right) p_{j}}{\left(\partial B / \partial p_{j}\right) p_{j}+\left(\partial B / \partial q_{j}\right) q_{j}}
$$




\section{Distortions in Non-Traded Goods Markets}

It is relatively straightforward to incorporate distortions in non-traded goods markets into the framework used so far. Let $\mathrm{c}$ and $\mathrm{h}$ denote respectively the producer and consumer prices of non-traded goods. Adding them to the list of arguments of the expenditure and GNP functions, the condition for equilibrium in non-traded goods markets may be written as:

$$
\mathrm{e}_{\mathrm{h}}(\mathrm{q}, \mathrm{h}, \mathrm{u})=\mathrm{gc}_{\mathrm{c}}(\mathrm{p}, \mathrm{c}, \mathrm{v}) \text {. }
$$

This may now be solved for the equilibrium producer price vector, $c$, which depends on all the exogenous variables including the vector of distortions in the non-traded goods markets themselves, $h-c$, which we write as $r$ :

$$
\mathrm{c}=\mathrm{c}(\tau, \mathrm{q}, \mathrm{p}, \mathrm{u}, \mathrm{v}) \text {. }
$$

The derivatives of this function are easily derived from (4.1); for example, the effect of changes in distortion levels $\tau$ on the producer prices $\mathrm{c}$ equals:

$$
c_{r}=\left(\mathrm{g}_{\mathrm{cc}}-\mathrm{e}_{\mathrm{hh}}\right)^{-1} \mathrm{e}_{\mathrm{hh}} \text {. }
$$

Incorporating this endogenous determination of $c$ (and hence, for given $\tau$, of $h$ ), the amended Balance of Trade Function becomes, instead of (2.1):

$$
\begin{aligned}
\mathrm{B}(\mathrm{p}, \mathrm{q}, \tau, \mathrm{u}) \equiv \mathrm{e}\{\mathrm{q}, \mathrm{h}(.), \mathrm{u}\} & -\mathrm{g}\{\mathrm{p}, \mathrm{c}(.), \mathrm{v}\}-\left(\mathrm{q}-\mathrm{p}^{*}\right)^{\prime} x\{\mathrm{q}, \mathrm{h}(.), \mathrm{u}\} \\
& +\left(\mathrm{p}-\mathrm{p}^{*}\right)^{\prime} \mathrm{y}\{\mathrm{p}, \mathrm{c}(.), \mathrm{v}\}-\mathrm{t}^{\prime} \mathrm{e}_{\mathrm{q}}\{\mathrm{q}, \mathrm{h}(.), \mathrm{u}\} .
\end{aligned}
$$

Consumer demands $\mathbf{x}$ now depend on the producer prices of traded goods $\mathrm{p}$ indirectly through their dependence on non-traded goods prices $h$; and similarly supplies depend indirectly on consumer prices q.

The Trade Restrictiveness Index may now be extended to the case where some goods are non-traded. Equation (2.7) becomes:

$$
\Delta\left(\mathbf{p}^{1}, \mathrm{q}^{1}, \tau^{1}, \mathrm{u}^{9}\right) \equiv\left[\Delta: \mathrm{B}\left(\mathrm{p}^{1} / \Delta, \mathrm{q}^{1} / \Delta, \tau^{1}, \mathrm{u}^{9}\right)=0\right] .
$$

Note that the index is defined by deflating $p$ and $q$ but not $\tau$. This reflects the fact that it is an index of trade restrictiveness: it equals the uniform scaling factor applied to tariffs alone which would compensate for the changes in distortions in both traded and non-traded sectors. 
Differentiating (2.7) to obtain the change in the index yields, instead of (2.9):

$$
\hat{\Delta}=\frac{\sum_{i}\left(B p_{i}\right) p_{i}+\sum_{j}\left(B g_{j}\right) q_{j}}{B_{p}^{\prime} p+B_{q}^{\prime} q}+\frac{B_{d}^{\prime} d \tau}{\Delta\left(B_{p}^{\prime} p+B_{q}^{\prime}\right)} .
$$

The first term on the right-hand side, relating $\hat{\Delta}$ to distortion changes in traded goods markets, is identical to that in (2.9), except that the derivatives of B must now take account of induced changes in the prices of non-traded goods. The second term, which incorporates the effects of distortion changes in non-traded good markets, is also estimable in principle, although a new feature introduced is that the level of $\Delta$ now appears in the denominator. This raises some additional issues in empirical applications, but they do not significantly reduce the applicability of the method. ${ }^{18}$

${ }^{18}$ This problem may be overcome by multiplying (4.6) by $\Delta$ and treating it as a first-order linear differential equation in $\Delta$ :

$$
\frac{d \Delta}{d t}=a \Delta+b
$$

where $\mathrm{a}$ and $\mathrm{b}$ are the two right-hand side coefficients of (4.6). The solution for $\Delta$ is:

$$
\Delta(t)=\left[\Delta(t-1)+\frac{b}{a}\right] e^{a}-\frac{b}{a} .
$$

In practical applications, where we must work with discrete data, we start with the difference equation analogous to (4.7) and solve to obtain:

$$
\Delta(t)=[(1+a) \Delta(t-1)+b] .
$$

This may be applied to each interval of change (each with different values of $a$ and $b$ ), along with the normalisation condition that $\Delta$ be equal to one in the initial period. 


\section{v Distortions in Factor Markets}

So far, we have assumed that the only forms of distortion are in final goods markets and that production is carried out efficiently within and between sectors. However, a significant number of distortions occurs in factor markets rather than in goods markets and it is desirable to have a method of quantifying their trade equivalents also. To do this we must go behind the economy-wide production structure given by the GNP function and allow for inefficiencies arising from differences in factor prices between sectors. ${ }^{19}$

To illustrate how this may be done, suppose that the economy can be divided into two sectors, labelled "1" and "2", such that factors are allocated efficiently within but not between the two sectors. Each of these "sectors" may itself be made up of a number of distinct sub-sectors. We assume that the only form of goods-market distortions are tariffs (so that $q$ equals p) and that import-competing goods are produced in sector $1 \mathrm{C}_{\mathrm{i} i \mathrm{j}}$. (These assumptions are made solely to simplify the exposition; the Appendix shows how they may be relaxed.) The assumption that factors are allocated efficiently within sectors 1 and 2 allows us to specify sectoral product functions $g^{1}\left(p, v^{1}\right)$ and $g^{2}\left(v^{2}\right)$ for each. The allocations of factors to sectors, represented by the vectors $v^{1}$ and $v^{2}$, are not given but adjust endogenously to meet the full-employment constraint:

$$
v^{1}+v^{2}=v
$$

and the factor-price constraint. A general way of specifying the latter, following Jones and Neary (1991), is to write the factor price vector in sector 1 , denoted by $\mathbf{w}^{1}$, as a function of the factor price vector in sector 2 , denoted by $w^{2}$, and of a vector of distortion parameters, denoted by $\boldsymbol{\gamma}$ :

$$
w^{1}=f\left(w^{2}, \gamma\right)
$$

This specification encompasses as special cases many important special forms of factor-market

\footnotetext{
19 A substantial literature developed in the 1970s dealing with factor-market distortions, although it paid relatively little attention to their implications for international trade itself; see for example, Jones (1971), Magee (1973) and Neary (1978). Our approach here is closest to Dixit and Norman (1980), Section 6.3, and to Jones and Neary (1991).
} 
distortion. To see this, differentiate (5.2) totally:

$$
d w^{1}=f_{w} d w^{2}+f_{\gamma} d \gamma .
$$

Different types of factor-market distortion may now be expressed in terms of restrictions 0.1 the elements of the two square matrices, $\mathrm{f}_{\mathrm{w}}$ and $\mathrm{f}_{\gamma}$. For example, absolute differentials imply that $f_{w}$ and $f_{\gamma}$ both equal the identity matrix, I; proportional differentials $\left(w^{1}=\Gamma w^{2}\right.$ where $\Gamma$ is the diagonal matrix formed from the vector $\gamma$ ) imply that $f_{w}$ equals $\Gamma$ and $f_{\gamma}$ equals $W$, the diagonal matrix formed from the vector $\mathrm{w}^{2}$; and sector-specific factor-price rigidities can be represented by setting all the elements in the corresponding rows of $\mathrm{f}_{\mathrm{w}}$ equal to zero. The production side of the model is completed by the assumption that factors are allocated efficiently within sectors, i.e., that factor prices are equal to sectoral value marginal products:

$$
w^{1}=g_{v}^{1}\left(p, v^{1}\right) \quad \text { and } \quad w^{2}=g_{v}^{2}\left(v^{2}\right) \text {. }
$$

The economy's total product is ti:en the sum of outputs from the two sectors:

$$
g(p, v, \gamma)=g^{1}\left\{p, v^{1}(.)\right\}+g^{2}\left\{v^{2}(.)\right\},
$$

where $\mathrm{v}^{1}$ and $\mathrm{v}^{2}$ are determined endogenously by (5.1), (5.2) and (5.4). (The derivatives of (5.5) are given ir the Appendix.)

The remaining steps in deriving the Trade Restrictiveness Index in the presence of factormarket distortions are familiar. The Balance of Trade Function for this model becomes:

$$
B(p, \gamma, u) \equiv e(p, u)-g(p, v, \gamma)-\left(p-p^{*}\right)^{\prime}\left[e_{p}(p, u)-g_{p}^{1}\left\{p, v^{1}(.)\right\}\right] .
$$

We are now able to define the Trade Restrictiveness Index for this model. Just as in Section II, it equals the proportional tariff surcharge factor which would compensate for the changes in both tariffe and factor-market distortions between periods 0 and 1 :

$$
\Delta\left(\mathrm{p}^{1}, \gamma^{1}, \mathrm{u}^{9}\right) \equiv\left[\Delta: \mathrm{B}\left(\mathrm{p}^{1} / \Delta, \gamma^{1}, \mathrm{u}^{9}\right)=0\right] .
$$

In proportional change form, this becomes: 
(5.8) $\quad \hat{\Delta}=\frac{\sum_{i}\left(B_{i} p_{i}\right) p_{i}}{B_{p}^{\prime} p}+\frac{B_{d \gamma}^{\prime} d \gamma}{\Delta B_{p}^{\prime} p}$.

' 1 is is similar to equation (4.6) and, like it, in principle poses no new problems of estimation. 


\section{An Application: The Tariff Equivalents of Mexican Agricultural Policy}

To illustrate the application of the Trade Restrictiveness Index, we turn next to a case study of an important phase in the liberalization of the Mexican economy: the reforms of agricultural policy in the late 1980's. Drawing on a more complete study (Anderson and Bannister, 1992), we calculate the change in the Trade Restrictiveness Index for ten crops over the five years 1985 to 1989 , taking account also of subsidies to fertilizer use.

As in most countries, the pattern of government intervention in Mexican agriculture is extremely complicated: most commodities are subsidized at both the consumer and producer levels and also benefit from input subsidies, especially to fertilizer use. Additional subsidies apply in the market for the single most important crop, maize (which accounts for over half of Mexican agricultural production and about a quarter of its agricultural imports). In particular, whole maize (which is a traded good) is the principal input into milled maize, which is a non-traded good and benefits from a subsidy. Table 1 shows the extent of the changes, over the period we consider, in the rates of subsidy to maize and to fertilizer use. The pattern of policy change revealed is a complicated one, with no clear inferences possible without the construction of some overall index number of policy restrictiveness. The standard producer and consumer subsidy equivalent indices can be constructed for this model and the picture they reveal is discussed below. However, their theoretical shortcomings have already been outlined in Section III. So it is desirable to apply the new measure we have introduced above.

For the particular application considered here, the version of the equation defining changes in $\Delta$ which we need to estimate is:

$$
\hat{\Delta}=\frac{\sum_{i}\left(B_{i} p_{i}\right) p_{i}+\sum_{j}\left(B_{j} q_{j}\right) q_{j}+B_{f} d f+(1 / \Delta) B_{i} d \tau}{B_{p}^{\prime} p+B_{q}^{\prime} q^{\prime}+B_{f} f} .
$$

where $p$ and $q$ denote producer and consumer prices of traded goods as before, $f$ denotes the domestic price of the traded input, fertilizer, and $\tau$ denotes the subsidy to milled maize use. To operationalize this equation, we require estimates of the supply and demand responses which underlie the derivatives of the balance of trade function, as given in equations (2.4) and (2.5). Ideally, these should come from a computable general equilibrium model but, as is typically the 
case in applied work, such a model, with a commodity disaggregation compatible with the set of policy instruments in which :/e are interested, has not been estimated for the Mexican agricultural sector. We must therefore have recourse to partial equilibrium estimates. For the present study, we assume that all cross-price elasticities are zero and take estimates of own-price elasticities of output supply and input demand from a study by Nathan and Associates (1990).

The results of using these elasticity estimates in equation (6.1) are given in the first row of Table $2 .^{20}$ The pattern of changes in trade restrictiveness revealed by the overall TRI is clearcut. The TRI shows a large increase in restrictiveness in 1986 and especially in 1987, followed by major reductions in restrictiveness in 1988 and 1989 . The cumulative effect of these changes is a $40.9 \%$ fall in trade restrictiveness over the four-year period.

As we noted at the end of Section III, it is possible to decompose the overall change in the TRI in order to pinpoint the sources of change. Firstly, we consider the decomposition by type of agricultural commodity. The next eleven rows of the Table show that the dominant influence on the overall index has been policy towards maize. However, it has not always been decisive: in 1986, for example, a significant tightening of policy in the sorghum market dominates a mild liberalization in maize policy to yield an overall rise in restrictiveness.

The next three rows in Table 2 present an alternative decomposition of the overall change in the TRI: this time, by type of instrument rather than by commodity group. Referring to equation (3.7), the first of these rows gives the calculated values of $\lambda \hat{\Delta}^{p}$, and analogously for the remaining two rows. This reveals that by far the bulk of the change in the index is accounted for by changes in production subsidies. Changes in consumption and fertiliser subsidies, by contrast, account for extremely small changes in the overall stance of policy.

Finally, it is of interest to compare the pattern of policy change revealed by the TRI with that suggested by the ad hoc producer and consumer subsidy equivalent indices. This is done in the final four rows of Table 2. The decomposition of changes in overall restrictiveness revealed by the "true" indices, $\Delta^{p}$ and $\Delta^{q}$, is similar to that revealed by the earlier decomposition

${ }^{20}$ Anderson and Bannister (1992) show that the results are not unduly sensitive to changes in the elasticity estimates used. 
by policy instrument. By contrast, the pattern of changes in the ad hoc PSE and CSE indices is completely different. Comparing first the PSE with $\Delta^{p}$, the movements in the two are in the same direction in only three of the four years and in those three years the magnitude of the change in $\Delta^{p}$ ranges from five to fourteen times that in the PSE. While the cumulative changes in the two indices are comparable, it is clear that the PSE is a totally inadequate guide to changes in the true index $\Delta^{p}$. Similar discrepancies between changes in the CSE and in the true consumer subsidy index $\Delta^{q}$ show that here too the ad hoc measure cannot be relied upon to provide an accurate reflection of the change in the restrictiveness of consumer price policies. Recalling that there is no consistent method of aggregating the PSE and CSE suggests that, despite the limitations of the TRI enforced by the need to ise crude elasticity estimates, there is no alternative to using it if we seek an index of the overall impact on trade of policy in domestic markets. 


\section{Conclusions and Suggestions for i'urther Research}

In this paper, we have proposed a new approach to evaluating the implications for international trade of domestic tax and subsidy policies. The r.easure meets a clear need, since the importance of domestic policies is increasing!.' reco;nised in trade negotiations and since consistent measures of the de'gree to which different countries have adopted trade-favoring policies are needed to test many of the hypotheses of the new literature on trade and growth. Moreover, the measures which have been used hitherto for these purposes have been shown to lack any theoretical foundation and to be unamenable to consistent aggregation. By contrast, the measure we have proposed in this paper has a secure foundation in standard welfare economics and permits consistent aggregation over different policy instruments and over different commodity groups.

Turning to applications, we have shown how our approach can be applied by considering a case study of changes in the trade restrictivene. : of Mexican agricultural policy from 1985 to 1989. The pattem of change during four years of important policy changes which our results reveal is of considerable interest in itself. More generally, the application presented in Section VI (and considered in much more detail by Anderson and Bannister (1992)), shows that the TRI incorporating changes in domestic policies can be successfully estimated using only the sort of existing parameter estimates (mainly own-price elasticities) which are available for many markets.

There are clearly many directions in which it would be desirable to extend the analysis of this paper. At the empirical level, it would be desirable to investigate the robustness of the estimates of trade restrictiveness to more satisfactory and comprehensive sets of parameter estimates. It would also be desirable to incorporate explicitly the effects of distortions in factor markets along the lines indicated in Section V. Finally, consistent estimates of the TRI for different countries should be calculated to illustrate the pattern of international differences in trade liberalization and to explore the effects of such liberalization on economic performance. As for the theoretical level, much remains to be done to extend the conceptual framework to incorporate distributional and intertemporal considerations, and to allow for more general specifications of the production sector. We believe that this research agenda promises to extend 
considerably our knowledge and understanding of the processes and effects of trade liberalization. 


\section{Appendix: Effects of Factor-Market Distortions}

In this Appendix, we provide further details on the behavior of the economy in the presence of factor-market distortions. Sections A.1 and A.2 show how to calculate the price and distortion derivatives of the GNP function and the output supply functions respectively. Tr se are a necessary step in calculating the derivatives of the Balance of Trade function (5.6), w ich are needed in order to evaluate the expression for $\hat{\Delta}$ in (5.8). Section A.3 then show, how the approach to modelling factor-market distortions adopted in Section $\mathbf{V}$ can be generalised to allow for any number of sectors, all of which may produce the import-col tpeting goods.

\section{A.1 Derivatives of the GNP Function: $g(p, v, \gamma)$}

The GNP function was defined in (5.5). Totally differentiatir ${ }^{\prime}$ this, making use of (5.1) and (5.4), gives:

$$
\text { (A.1) } d g=g_{p}^{1} \cdot d p+\left(w^{1}-w^{2}\right)^{\prime} d v^{1} \text {. }
$$

To eliminate the changes in factor allocations from thin, differentiate (5.4) and combine with (5.3) to obtain:

$$
d v^{1}=\left(g_{v v}^{1}+f_{w} g_{v v}^{2}\right)^{-1}\left[-g_{v p}^{1} d p+f_{\gamma} d{ }^{\prime}\right] .
$$

Substituting into (A.1) and collecting terms gives the expressions we seek for the effects of price and distortion changes on GNP:

$$
\begin{aligned}
& g_{p}=g_{p}^{1}-\left(w^{1}-w^{2}\right)^{\prime}\left({ }^{1}{ }_{w}+i_{w} g_{w}^{2}\right)^{-1} g^{1}{ }_{v p} \\
& g_{\gamma}=\left(w^{1}-w^{2}\right)^{\prime}\left(g_{w}^{1}+f_{w}{ }^{2}{ }_{w}\right)^{-1} f_{\gamma} .
\end{aligned}
$$

In both these equations, a key ${ }_{1}$ atriv is $\left(g_{v v}^{1}+f_{w} g^{2}{ }_{v v}\right)^{-1}$, which gives the effects of higher factor prices in sector $1, w^{1}$, on empioyment levels there, $v^{1}$. In the case of absolute factor-price differentials, $f_{w}$ collapse to the :dentity matrix and the key matrix is negative definite. But nothing can be sa'd a':ou! its propertics in general. In equation (A.3), the first term on the right-laxd side, $s_{p}^{1}$, is the vector of outputs of import-competing goods, $y^{1}$. In the presence of 
distortions, this / liffers from the price derivative of GNP by the second term: if the matrix $\left(g_{w}^{1}+f_{w} g_{w}^{2}\right)^{-1}$ is negative definite, this term tends to encourage a further increase in GNP whenever a price increase tends to raise the returns in sector 1 of those factors which are paid higher premia there (i.e., whenever the vectors $\left(w^{1}-w^{2}\right)$ and $g^{1}{ }_{v p}$ are positively correlated). As for equation (A.4), its interpretation is straightforward when the disto tions take the form of absolute price differentials, implying that a proportionate reduction in distortions will raise GNP.

\section{A.2 Derivatives of the Output Supply Functions: $y^{1}(p, v, \gamma)=g_{p}^{1}\left\{p, v^{1}().\right\}$}

Differentiating totally the equation for the output supply functions, making use of (A.2), gives the required derivatives:

$$
y_{p}^{1}=g_{p p}^{1}-g_{p v}^{1}\left(g_{w}^{1}+f_{w} g_{w}^{2}\right)^{-1} g_{v p}^{1},
$$

where the second term takes account of the induced factor reallocation between sectors; and:

$$
y_{\gamma}^{1}=g_{p v}^{1}\left(g_{w}^{1}+f_{w} g_{w}^{2}\right)^{-1} f_{\gamma} .
$$

Once again, these derivatives have a straightforward interpretation with absolute intersectoral factor-price differentials. But, more generally, as is well-known from the literature on factormarket distortions in the two-sector model, perverse price-output and distortion-output responses are possible. ${ }^{21}$

\section{A.3 The GNP Function with Many Sectors}

The assumption that factors are allocated efficiently within each sector allows us to specify sectoral product functions for each:

$$
g^{\prime}\left(p^{\prime}, \nu\right)=\operatorname{Max}_{x_{1}}\left[p^{i} \cdot x^{\prime}: F^{\prime}\left(x^{\prime}, \nu\right)=0\right] \quad i=1, \ldots n,
$$

where $F^{i}\left(x^{i}, v^{i}\right)=0$ is the production constraint for sector $i$, summarising the technology there

As in Neary (1978), stability arguments can be invoked to place restrictions on the comparative statics responses, but their interpretation is more difficult with more than two factors or sectors. 
which is assumed to be convex. As for the distortions themselves, a general way of specifying them, following Jones and Neary (1991), is to extend equation (5.2) by writing the factor price vector in sector $i$, denoted by $w$ ', as a function of a vector of "free" or undistorted factor prices, denoted by $w$, and of a vector of sector-specific distortion parameters, denoted by $\gamma$ :
(A.8)
$\mathbf{w}^{\mathrm{i}}=\mathbf{f}^{\mathrm{i}}\left(\mathbf{w}, \gamma^{\mathrm{i}}\right)$
$\mathrm{i}=1, \ldots \mathrm{n}$.

The free factor prices $w$ will typically be associated with the actual factor prices in at least one sector of the economy; nevertheless the symmetric specification is more convenient.

The production side of the general model is completed by adding the marginal productivity conditions:
(A.9) $\quad w^{i}=g_{v}^{i}\left(p, v^{i}\right)$
$\mathrm{i}=1, \ldots \mathrm{n}$;

the full-employment constraint:
(A.10)
$\Sigma v^{i}=v ;$

and the fact that GNP equals the sum of sectoral products:

$$
\text { (A.11) } g\left(p, v,\left\{\gamma^{i}\right\}\right)=\Sigma g^{i}\left(p, v^{i}\right) \text {. }
$$

The $2 n+1$ vector equations (A.7), (A.9) and (A.10) can now be solved for the $2 n+1$ vector unknowns, $\left\{w^{i}\right\},\left\{v^{i}\right\}$ and $w$; and substituting the results into (A.11) allows us to proceed as in the text. 


\section{References}

Anderson, J.E. (1988): The Relative Inefficiency of Quotas, Cambridge, Mass.: M.I.T. Press.

Anderson, J.E. (1991): "The coefficient of trade utilisation: The cheese case," in R. Baldwin (ed.): Empirical Studies of Commercial Policy, Chicago: University of Chicago Press, 221-244.

Anderson, J.E. (1992): "Tariff index theory," World Bank Policy Research Working Papers in International Trade No. WPS1023, Washington, D.C.: The World Bank, November.

Anderson, J.E. and G. Bannister (1992): "The trade restrictiveness index: An application to Mexican agriculture," World Bank Policy Research Working Papers in International Trade No. WPS874, Washington D.C.: The World Bank.

Anderson, J.E. and J.P. Neary (1990): "The coefficient of trade utilisation: Back to the Baldwin Envelope," in R.W. Jones and A.O. Krueger (eds.): The Political Economy of. International Trade: Essays in Honour of Robert Baldwin, Oxford: Basil Blackwell, 49-72.

Anderson; J.E. and J.P. Neary (1992a): "Trade reform with quotas, partial rent retention and tariffs," Econometrica, 60, 57-76.

Anderson, J.E. and J.P. Neary (1992b): "A new approach to evaluating trade policy," World Bank Policy Research Working Papers in International Trade No. WPS1022, Washington, D.C.: The World Bank, November.

Bertrand, T.J. and J. Vanek (1971): "The theory of tariffs, taxes and subsidies: Some aspects of the second best," American Economic Review, 61, 925-931.

Bruno, M. (1972): "Market distortions and gradual reform," Review of Economic Studies, 39, 373-383.

Corden, W.M. (1966): "The effective protective rate, the uniform tariff equivalent and the average tariff," Economic Record, 200-216.

Corden, W.M. (1984): "The theory of protection," in R.W. Jones and P.B. Kenen (eds.): Handbook of International Economics, Volume 1, Amsterdam: North-Holland.

Corden, W.M. and R.E. Falvey (1985): "Quotas and the Second Best, " Economics Letters, 18, 67-70. 
Deaton, A.S. (1979): "The distance function in consumer behaviour with applications to index numbers and optimal taxation," Review of Economic Studies, 46, 391-405.

Debreu, G. (1951): "The coefficient of resource utilization," Econometrica, 19, 273-292.

Diewert, E. (1985): "A dynamic approach to the measurement of waste in an open economy," Journal of International Economics, 19, 213-240.

Dixit, A.K. (1987): "Tax policy in open economies," in A. Auerbach and M. Feldstein (eds.): Handbook of Public Economics, Amsterdam: North-Holland, 313-374.

Dixit, A.K. and V. Norman (1980): Theory of International Trade: A Dual, General Equilibrium Approach, London: Cambridge University Press.

Falvey, R.E. (1988): "Tariffs, quotas and piecemeal policy reform," Journal of International Economics, 25, 177-183.

Foster, E. and H. Sonnenschein (1970): "Price distortion and economic welfare, " Econometrica, 38, 281-297.

Hatta, T. (1977): "A theory of piecemeal policy recommendations, " Review of Economic Studies, 44, 1-21.

Jones, R.W. (1971): "Distortions in factor markets and the general equilibrium model of production," Journal of Political Economy, 79, 437-459.

Jones, R.W. and J.P. Neary (1991): "Wage sensitivity rankings and temporal convergence," in E. Helpman and A. Razin (eds.): International Trade and Trade Policy, Cambridge, Mass.: M.I.T. Press, 270-288.

Lloyd, P.J. (1974): "A more general theory of price distortions in open economies," Journal of Intermational Economics, 4, 365-386.

Magee, S.P. (1973): "Factor market distortions, production and trade: A survey," Oxford Economic Papers, 25, 1-43.

Nathan Associates, Inc. (1990), "Comermax; A Multimarket Model of Mexico's Agriculture," Inter-American Development Bank, Washington, D.C.

Neary, J.P. (1978): "Dynamic stability and the theory of factor-market distortions," American Economic Review, 68, 671-683.

Neary, J.P. (1988): "Tariffs, quotas and voluntary export restraints with and without internationally mobile capital," Canadian Journal of Economics, 21, 714-735. 
Neary, J.P. (1989): "Trade liberalisation and shadow prices in the presence of tariffs and quotas," Working Paper No. 89/4, Centre for Economic Research, University Cullege Dublin.

OECD (1991): Producer Subsidy Equivalent and Consumer Subsidy Equivalent Tables, 1979 to 1990, Paris. 


\begin{tabular}{||l|lllll|}
\hline & 1985 & 1986 & 1987 & 1983 & 1989 \\
\hline $\begin{array}{c}\text { Producer Subsidy } \\
\left(\mathrm{p}-\mathrm{p}^{*}\right) / \mathrm{p}^{*}\end{array}$ & 0.32 & 0.28 & 0.63 & 0.39 & 0.01 \\
$\begin{array}{c}\text { Consumer Subsidy } \\
\left(\mathrm{p}^{*}-\mathrm{q}\right) / \mathrm{p}^{*}\end{array}$ & 0.31 & 0.40 & 0.08 & 0.20 & 0.35 \\
$\begin{array}{c}\text { Nontraded Good Subsidy } \\
(\mathrm{c}-\mathrm{h}) / \mathrm{c}\end{array}$ & 0.71 & 0.39 & 0.24 & 0.27 & 0.27 \\
$\begin{array}{c}\text { Fertilizer Input Subsidy } \\
\left(\mathrm{f}^{*} \mathrm{f}\right) / \mathrm{f}^{*}\end{array}$ & 0.69 & 0.68 & 0.64 & 0.59 & 0.55 \\
\hline
\end{tabular}

Table 1: Primary Distortions in Maize and Fertilizer 


\begin{tabular}{|c|c|c|c|c|c|}
\hline & 1986 & 1987 & 1988 & 1989 & $\begin{array}{c}\text { Cumulative } \\
1985-89\end{array}$ \\
\hline TRI: & 7.5 & 40.2 & -40.3 & -34.3 & -40.9 \\
\hline \multicolumn{6}{|l|}{$\begin{array}{l}\text { Decomposition by } \\
\text { Commodity: }\end{array}$} \\
\hline Maize & -3.9 & 38.8 & -23.4 & -29.3 & \\
\hline Sorghum & 17.5 & -7.9 & 0.7 & -3.3 & \\
\hline Wheat & -1.3 & 0.4 & 1.0 & -3.6 & \\
\hline Soy Bean & -2.0 & 5.1 & -6.2 & 4.4 & \\
\hline Dry Bean & -2.9 & -0.1 & 0.3 & -0.3 & \\
\hline Barley & 0.2 & -0.3 & 0.3 & -0.2 & \\
\hline Cottonseed & 0.3 & 5.4 & -11.1 & -0.8 & \\
\hline Sesame Seed & 0.0 & 0.3 & -0.1 & 0.4 & \\
\hline Sunflower Seed & 0.0 & 0.0 & 0.0 & 0.0 & \\
\hline Coffee & 0.1 & 0.0 & 0.4 & -0.1 & \\
\hline Fertilizer & -0.5 & -1.5 & -2.0 & -1.4 & \\
\hline \multicolumn{6}{|l|}{$\begin{array}{l}\text { Decomposition by Policy } \\
\text { Instrument: }\end{array}$} \\
\hline Production Subsidy & 7.1 & 43.4 & -41.4 & -28.7 & \\
\hline Consumption Subsidy & 0.9 & -1.6 & 3.2 & -4.2 & \\
\hline Input (Fertilizer) Subsidy & -0.5 & -1.5 & -2.0 & -1.4 & \\
\hline \multicolumn{6}{|l|}{$\begin{array}{l}\text { Comparison of True and } A d \\
H o c \text { Sub-Indices: }\end{array}$} \\
\hline PSE & -7.4 & 2.4 & -4.9 & -5.9 & -15.1 \\
\hline$\Delta^{p}$ & 7.1 & 34.4 & -31.6 & -30.1 & -31.2 \\
\hline CSE & -6.4 & 15.3 & 32.5 & -31.0 & -1.3 \\
\hline$\Delta^{q}$ & -79.8 & -11.4 & 69.7 & -7.9 & -72.0 \\
\hline
\end{tabular}

-Tahle 2: The TRI and its Components (\% changes per annum) 


\section{Pollcy Research Working Paper Serles}

\begin{tabular}{|c|c|c|c|c|}
\hline & Title & Author & Date & for paper \\
\hline WPS1151 & $\begin{array}{l}\text { Is Growth Bad for the Environment? } \\
\text { Pollution, Abatement, and } \\
\text { Endogenous Growth }\end{array}$ & $\begin{array}{l}\text { Charles van Marrewijk } \\
\text { Federick van der Ploeg } \\
\text { Jos Verbeek }\end{array}$ & July 1993 & $\begin{array}{l}\text { J. Verbeek } \\
33935\end{array}$ \\
\hline WPS1152 & $\begin{array}{l}\text { Population, Health, and Nutrition: } \\
\text { Annual Operational Review for Fiscal } \\
1992\end{array}$ & $\begin{array}{l}\text { Denise Vaillancourt } \\
\text { Stacye Brown } \\
\text { and Others }\end{array}$ & July 1993 & $\begin{array}{l}\text { O. Nadora } \\
31091\end{array}$ \\
\hline WPS1153 & $\begin{array}{l}\text { North American Free Trade } \\
\text { Agreement: Issues on Trade in } \\
\text { Financial Services for Mexico }\end{array}$ & $\begin{array}{l}\text { Alberto Musalem } \\
\text { Dimitri Vittas } \\
\text { Asll Demirgüç-Kunt }\end{array}$ & July 1993 & $\begin{array}{l}\text { P. Infante } \\
37664\end{array}$ \\
\hline WPS1154 & Options for Pension Reform in Tunisia & Dimitri Vittas & July 1993 & $\begin{array}{l}\text { P. Infante } \\
37664\end{array}$ \\
\hline WPS1155 & $\begin{array}{l}\text { The Regulation and Structure of } \\
\text { Nonlife Insurance in the United } \\
\text { States }\end{array}$ & $\begin{array}{l}\text { Martin F. Grace } \\
\text { Michael M. Barth }\end{array}$ & July 1993 & $\begin{array}{l}\text { P. Infante } \\
37664\end{array}$ \\
\hline WPS1156 & $\begin{array}{l}\text { Tropical Timber Trade Policies: What } \\
\text { Impact Will Eco-Labeling Have? }\end{array}$ & $\begin{array}{l}\text { Panayotis N. Varangis } \\
\text { Carlos A. Primo Braga } \\
\text { Kenji Takeuchi }\end{array}$ & July 1993 & $\begin{array}{l}\text { D. Gustafson } \\
33714\end{array}$ \\
\hline WPS1157 & $\begin{array}{l}\text { Intertemporal and Interspatial } \\
\text { Comparisons of Income: The Meaning } \\
\text { of Relative Prices }\end{array}$ & Sultan Ahmad & July 1993 & $\begin{array}{l}\text { E. O-Reilly- } \\
\text { Campbell } \\
33707\end{array}$ \\
\hline WPS1158 & $\begin{array}{l}\text { Population Growth, Externalities. } \\
\text { and Poverty }\end{array}$ & $\begin{array}{l}\text { Nancy Birdsall } \\
\text { Charles Griftin }\end{array}$ & July 1993 & $\begin{array}{l}\text { E. Hornsby } \\
35742\end{array}$ \\
\hline WPS1159 & $\begin{array}{l}\text { Stock Market Development and } \\
\text { Financial Intermediary Growth: } \\
\text { A Research Agenda }\end{array}$ & $\begin{array}{l}\text { Asli Demirgüç-Kunt } \\
\text { Ross Levine }\end{array}$ & July 1993 & $\begin{array}{l}\text { P. Sintim- } \\
\text { Aboagye } \\
38526\end{array}$ \\
\hline WPS1160 & $\begin{array}{l}\text { Equity and Bond Flows to Asia and } \\
\text { and Latin America: The Role of Global } \\
\text { and Country Factors }\end{array}$ & $\begin{array}{l}\text { Punam Chuhan } \\
\text { Stijn Claessens } \\
\text { Nlandu Mamingi }\end{array}$ & July 1993 & $\begin{array}{l}\text { Rose Vo } \\
31047\end{array}$ \\
\hline WPS1161 & $\begin{array}{l}\text { Increasing Women's Participation in } \\
\text { the Primary School Teaching Force and } \\
\text { Teacher Training in Nepal }\end{array}$ & Molly Maguire Teas & July 1993 & $\begin{array}{l}\text { L. Maningas } \\
80380\end{array}$ \\
\hline WPS1162 & $\begin{array}{l}\text { The Slovenian Labor Market in } \\
\text { Transition: Issues and Lessons } \\
\text { Learned }\end{array}$ & $\begin{array}{l}\text { Milan Vodopivec } \\
\text { Samo Hribar-Milic }\end{array}$ & July 1993 & $\begin{array}{l}\text { S. Moussa } \\
39019\end{array}$ \\
\hline WPS1163 & $\begin{array}{l}\text { Domestic Distortions and } \\
\text { International Trade }\end{array}$ & $\begin{array}{l}\text { James E. Anderson } \\
\text { J. Peter Neary }\end{array}$ & July 1993 & $\begin{array}{l}\text { D. Gustafson } \\
33714\end{array}$ \\
\hline
\end{tabular}


Pollcy Research Working Paper Serles

Titie

WPS1164 Power, Distortions, Revolt, and Reform in Agricultural Land Relations
Author

Hans P. Binswanger

Klaus Deininger

Gershon Feder
Contact

Date

for paper

H. Binswanger 31871 